Research

Open Access

\title{
Ventilator-associated pneumonia in patients undergoing major heart surgery: an incidence study in Europe
}

\author{
Javier Hortal' ${ }^{1}$, Patricia Muñoz ${ }^{2,6}$, Gregorio Cuerpo ${ }^{3}$, Hector Litvan ${ }^{4}$, Peter M Rosseel5, \\ Emilio Bouza ${ }^{2,6}$ for the European Study Group on Nosocomial Infections and for the European \\ Workgroup of Cardiothoracic Intensivists
}

\author{
${ }^{1}$ Anaesthesia Department. Hospital General Universitario Gregorio Marañón. Dr. Esquerdo 46 - 28007 Madrid, Spain \\ ${ }^{2}$ Clinical Microbiology and Infectious Diseases Department. Hospital General Universitario Gregorio Marañón. Dr. Esquerdo 46 - 28007 Madrid, \\ Spain \\ ${ }^{3}$ Cardiac Surgery Department. Hospital General Universitario Gregorio Marañón. Dr. Esquerdo 46 - 28007 Madrid, Spain \\ ${ }^{4}$ Anaesthesia Department. Hospital Sant Creu i Sant Pau. Sant Antoni Maria Claret, 167 - 08025 Barcelona, Spain \\ ${ }^{5}$ Anaesthesia and Critical Care Department. Thoraxcenter Amphia. Galderseweg 81 - 4836AE Breda, Holland \\ ${ }^{6}$ Centro de Investigación Biomédica en Red de Enfermedades Respiratorias, Fundación Caubet-Cimera, Recinto Hospital Joan March, Carretera \\ Soller Km 12, 07110, Bunyola, Mallorca, Spain
}

Corresponding author: Javier Hortal, fcojavier.hortal@madrid.org

Received: 24 Oct 2008 Revisions requested: 19 Nov 2008 Revisions received: 7 Mar 2009 Accepted: 22 May 2009 Published: 22 May 2009

Critical Care 2009, 13:R80 (doi:10.1186/cc7896)

This article is online at: http://ccforum.com/content/13/3/R80

(c) 2009 Hortal et al.; licensee BioMed Central Ltd.

This is an open access article distributed under the terms of the Creative Commons Attribution License (http://creativecommons.org/licenses/by/2.0), which permits unrestricted use, distribution, and reproduction in any medium, provided the original work is properly cited.

\begin{abstract}
Introduction Patients undergoing major heart surgery (MHS) represent a special subpopulation at risk for nosocomial infections. Postoperative infection is the main non-cardiac complication after MHS and has been clearly related to increased morbidity, use of hospital resources and mortality. Our aim was to determine the incidence, aetiology, risk factors and outcome of ventilator-associated pneumonia (VAP) in patients who have undergone MHS in Europe.
\end{abstract}

Methods Our study was a prospective study of patients undergoing MHS in Europe who developed suspicion of VAP. During a one-month period, participating units submitted a protocol of all patients admitted to their units who had undergone MHS.

Results Overall, 25 hospitals in eight different European countries participated in the study. The number of patients intervened for MHS was 986. Fifteen patients were excluded because of protocol violations. One or more nosocomial infections were detected in $43(4.4 \%)$ patients. VAP was the most frequent nosocomial infection $(2.1 \% ; 13.9$ episodes per
1000 days of mechanical ventilation). The microorganisms responsible for VAP in this study were: Enterobacteriaceae (45\%), Pseudomonas aeruginosa (20\%), methicillin-resistant Staphylococcus aureus (10\%) and a range of other microorganisms. We identified the following significant independent risk factors for VAP: ascending aorta surgery (odds ratio $(\mathrm{OR})=6.22 ; 95 \%$ confidence interval $(\mathrm{Cl})=1.69$ to 22.89), number of blood units transfused (OR $=1.08$ per unit transfused; $95 \% \mathrm{Cl}=1.04$ to 1.13 ) and need for re-intervention (OR $=6.65 ; 95 \% \mathrm{Cl}=2.10$ to 21.01 ). The median length of stay in the intensive care unit was significantly longer $(P<$ $0.001)$ in patients with VAP than in patients without VAP $(23$ days versus 2 days). Death was significantly more frequent $(P<$ $0.001)$ in patients with VAP (35\% versus $2.3 \%)$.

Conclusions Patients undergoing aortic surgery and those with complicated post-intervention courses, requiring multiple transfusions or re-intervention, constitute a high-risk group probably requiring more active preventive measures.

\footnotetext{
CABG: coronary artery bypass grafting; Cl: confidence interval; CPB: cardiopulmonary bypass; CPIS: Clinical Pulmonary Infection Score; ESCMID: European Society of Clinical Microbiology and Infectious Diseases; ESGNI: European Study Group of Nosocomial Infection; EWCI: European Working Party of Cardiothoracic Intensivists; $\mathrm{FiO}_{2}$ : fraction of inspired oxygen; ICU: intensive care unit; IQR: interquartile range; MHS: major heart surgery; NYHA: New York Heart Association; OR: odds ratio; $\mathrm{PaO}_{2}$ : partial pressure of arterial oxygen; RR: relative risk; SD: standard deviation; VAP: ventilator-associated pneumonia.
} 


\section{Introduction}

Patients undergoing major heart surgery (MHS) represent a special subpopulation at risk for nosocomial infections. Postoperative infection is the main non-cardiac complication after $\mathrm{MHS}$ and has been clearly related to increased morbidity, use of hospital resources and mortality $[1,2]$.

Ventilator-associated pneumonia (VAP) is the most common infection in patients admitted to intensive care units (ICUs) $[3,4]$ and is a leading cause of morbidity and mortality $[5,6]$. The situation of VAP in patients undergoing MHS has been assessed only from the perspective of single institutions with the bias of the case-mix at a particular centre [1,7-10]. Our group led the collection of retrospective data of VAP in MHS from several European institutions [11], but prospective data from a large group of European centres were lacking.

Our study aims were to determine the incidence, aetiology, risk factors and outcome of VAP in a large sample of patients who have undergone MHS in Europe.

\section{Materials and methods}

Our study is a joint venture between the European Study Group of Nosocomial Infection (ESGNI), the European Society of Clinical Microbiology and Infectious Diseases (ESCMID) and the European Working Party of Cardiothoracic Intensivists (EWCl). The Ethics Committee of Hospital General Universitario Gregorio Marañón (Madrid, Spain) approved the study and indicated that individual informed consent was not necessary in this study because no intervention was performed and confidentiality was respected.

Our study (ESGNI 09 study) was a prospective (one-month enrolment) analysis of patients undergoing $\mathrm{MHS}$ in Europe who developed suspicion of VAP. During a one-month period participating units submitted a protocol of all patients admitted to their units who had undergone MHS. Specific variables on VAP diagnosis and evolution were included.

Units and investigators willing to participate sent data regarding the type of hospital, (public or private, teaching or nonteaching, total population surveyed, number of beds, and the number of hospital admissions for 24 hours or longer during the month of the study) and data regarding the ICU used for postoperative care of MHS patients in each institution (ICU specific for MHS or mixed with other types of patients and number of beds available).

Individual data for patients admitted to European postsurgical ICUs included: hospital admission date, sex, age, prior illnesses, clinical characteristics of the patient and New York Heart Association (NYHA) functional class. Patients' underlying diseases were classified according to the criteria of McCabe and Jackson [12] as rapidly fatal, ultimately fatal and non-fatal; their morbidity scores were based on the Charlson co-morbidity index [13]. The American Society of Anesthesiologists physical status grading system [14] and EuroSCORE [15] were used to value surgical risk.

Data regarding the surgical procedure included type of indication (elective, urgent or emergent), type of surgical procedure, duration (from the skin incision until closure), time on cardiopulmonary bypass, aortic cross-clamp time, surgical antimicrobial prophylaxis, transfusion needs, overall period with chest drainages, number of reinterventions and need for inotropic support, intra-aortic balloon or circulatory assistance. Surgical prophylaxis was performed according to each centre's protocol.

Recorded postsurgical events included ICU admission and discharge date, days spent on mechanical ventilation, preventive methods for VAP, type of nosocomial infection and patient evolution. If the patient had VAP, a specific part of the questionnaire was completed including criteria for diagnosis, Clinical Pulmonary Infection Score (CPIS) [16], microbiological data (microorganisms causing pneumonia) and outcome.

\section{Definitions}

VAP was diagnosed upon the presence of new and/or progressive pulmonary infiltrates on chest radiograph plus two or more of the following criteria: fever $\left(\geq 38.5^{\circ} \mathrm{C}\right)$ or hypothermia $\left(<36^{\circ} \mathrm{C}\right)$, leucocytosis $\left(\geq 12 \times 10^{9} / \mathrm{L}\right)$, purulent tracheobronchial secretions or a reduction of partial pressure of arterial oxygen $\left(\mathrm{PaO}_{2}\right)$ /fraction of inspired oxygen $\left(\mathrm{FiO}_{2}\right)$ of $15 \%$ or higher in the past 48 hours according to the definitions of the Centers for Disease Control and Prevention [17]. Also, as pneumonia cases we included those patients with a CPIS higher than six [16].

Tracheobronchitis was defined as the presence of purulent tracheobronchial secretions plus two or more of the following criteria: fever $\left(\geq 38.5^{\circ} \mathrm{C}\right)$ or hypothermia $\left(<36^{\circ} \mathrm{C}\right)$, leucocytosis $\left(\geq 12 \times 10^{9} / \mathrm{L}\right)$, or significant bacteriological counts in respiratory secretions in patients without pulmonary infiltrates suggesting pneumonia on chest radiograph [17]. Cases with either VAP or tracheobronchitis had to be microbiologically confirmed.

The ICUs were classified as specific if more than 95\% of their beds were addressed to patients undergoing MHS or as mixed if this criterion was not met.

\section{Data analysis}

Reports from individual centres were sent to the coordinating centre either by regular mail or via the internet. Individual reports were reviewed by one of the authors before being entered into the database and analysed using SPSS Version 12 (SPSS Inc., Chicago, IL, USA). 
We expressed continuous variables as the median and interquartile range (IOR) if their distribution was skewed, and discrete variables as percentages. Measures of significance were assessed by univariate and stratified analysis. Continuous variables were analysed by the Mann-Whitney $U$ test, and categorical variables were analysed with Fisher's exact test or the chi-squared test. All statistical tests were two-tailed. The independent contribution of predictor variables for the development of VAP and mortality after MHS was assessed by stepwise logistic regression analysis, and associations between variables expressed as odds ratios (OR) and respective 95\% confidence intervals $(\mathrm{Cl})$. As candidate variables we included in the model all those which showed univariate significance less than $P<0.1$. The aim of the study was to find pre- operative, operative and immediate postoperative risk factors of VAP. For this reason risk factors were analysed in two models, with and without the inclusion of the number of days of mechanical ventilation. The models were validated by means of the jack-knifing technique [18]. Variables which did not yield the same results in at least $90 \%$ of the 20 jack-knifing runs were discarded. No significant first-order interactions were found in the models.

\section{Results}

Participating institution characteristics

Overall, 25 hospitals in eight different European countries participated in the study (Table 1). The participating institutions were either teaching $(88 \%)$ or non-teaching hospitals $(12 \%)$

\section{Table 1}

\begin{tabular}{|c|c|c|c|}
\hline Country & Hospitals & Patients per hospital & Patients per country \\
\hline Austria & AKH University Hospital & 19 & 19 \\
\hline Denmark & Rigshospitalet & 72 & 72 \\
\hline France & Albert Michallon & 35 & 35 \\
\hline Italy & Azienda Ospedaliera-Universita di Padova & 64 & 64 \\
\hline The Netherlands & Amphia Hospital & 134 & 134 \\
\hline \multirow[t]{17}{*}{ Spain } & Sant Creu i Sant Pau & 59 & 487 \\
\hline & German Trias i Pujol & 19 & \\
\hline & Virgen de las Nieves & 26 & \\
\hline & Clínico de San Carlos & 16 & \\
\hline & Clínico Universitario de Valencia & 22 & \\
\hline & Hospital Universitario 12 de Octubre & 32 & \\
\hline & Hospital de Cruces & 23 & \\
\hline & Mixoeiro & 55 & \\
\hline & Puerta de Hierro & 24 & \\
\hline & Hospital de la Princesa & 23 & \\
\hline & Virgen de la Macarena & 39 & \\
\hline & Gregorio Marañón & 39 & \\
\hline & Clínica Ruber & 13 & \\
\hline & Hospital Universitario de Canarias & 20 & \\
\hline & Ruber Internacional & 4 & \\
\hline & Hospital la Fe & 38 & \\
\hline & Virgen de la Arrixaca & 35 & \\
\hline Sweden & Sahlgrens University Hospital & 69 & 69 \\
\hline \multirow[t]{2}{*}{ Switzerland } & University Hospital Zurich & 67 & 91 \\
\hline & Centre Hospitalier Universitaire de Vaudois & 24 & \\
\hline Totals $=8$ & 25 & & 971 \\
\hline
\end{tabular}


and the majority were public centres (92\%). The distribution of hospitals according to the number of beds was as follows: less than 500 beds (16\%), from 500 to 1000 beds (48\%) and more than 1000 beds (36\%). Overall, these institutions had performed 13,357 (IQR $=303$ to 675 ) MHS procedures during the previous year. Considering that they were responsible for the health care of $18,173,745$ people (IQR $=400,000$ to $1,200,000$ ) and they had had 996,780 admissions (IQR $=$ 24,900 to 62,500 ) during the previous year, we can estimate that there were $73.8 \mathrm{MHS}$ interventions per 100,000 population and 13.4 procedures per 1000 hospital admissions in the areas covered by the participant institutions.

Only 44\% of the ICUs surveyed were used specifically for MHS patients and the median number of available beds in these units was 12 (IOR $=10$ to 22 ).

\section{Population at risk}

The number of patients intervened for MHS during the study period in the different participating centres was 986 (Median $=33, \operatorname{IQR}=21$ to 58 ). Fifteen patients were excluded because of protocol violations. Overall, 971 patients remained in the study. General data regarding the population intervened including the demographic and descriptive data of the patients are listed in Table 2. The mean (standard deviation (SD)) age of the patients was 64.22 (12.11) years and the median length of in hospital preoperative stay was two days (IQR $=$ one to seven).

The interventions were classified as elective in $80.4 \%$ of the patients, urgent in $15.2 \%$ and emergent in $4.3 \%$. The antimicrobial prophylaxis used was cefazolin (37.8\%), vancomycin $(4.6 \%)$, other drugs $(57.3 \%)$ and none $(0.3 \%)$. The mean duration of surgery was 233 (96) minutes. Of the 523 patients undergoing coronary artery bypass grafting (CABG), 122 (23.3\%) were performed without cardiopulmonary bypass (CPB). The mean CPB time was 110.1 (54.1) minutes and the mean aortic cross-clamp time was 71.9 (42.2) minutes.

Overall, 477 patients (49.1\%) were transfused and the median number of units was three (IQR $=$ two to six). The patients needed inotropic support (59.1\%), intra-aortic balloon $(6.1 \%)$ or circulatory assistance $(0.5 \%)$ because of different degrees of ventricular dysfunction. The median length of stay in the ICU was two days (IQR = one to three).

\section{Ventilator-associated pneumonia}

Of the 971 patients undergoing MHS, 43 (4.4\%) patients had one or more nosocomial infection (Figure 1). VAP was the most frequent nosocomial infection, with an incidence during the study period of $2.1 \%$ (20 of 971 patients). Of these, five patients $(25 \%)$ had two VAP episodes. The incidence density of VAP in this study was 13.9 episodes per 1000 days of mechanical ventilation.
Overall, only 112 patients (11.5\%) required more than 48 hours of mechanical ventilation and $66(6.8 \%)$ more than 72 hours. If we consider only the patients with more than 48 hours of mechanical ventilation, $17.9 \%$ (20 of 112) developed VAP and the incidence reached $28.8 \%$ among those ventilated for more than 72 hours (19 of 66). The mean CPIS of these patients was 7.5 (1.6) points and the median number of days on mechanical ventilation at the time of VAP was 5.5 days (IQR $=3.0$ to 7.7). VAP patients required a median number of 15 days of mechanical ventilation (IOR $=6.2$ to 29.7 ).

In our study, seven patients (0.7\%) fulfilled criteria for tracheobronchitis at any time during their clinical course. The incidence rate of tracheobronchitis was 3.7 per 1000 days of mechanical ventilation. If we consider only the patients with more than 72 hours of mechanical ventilation, 10.6\% (7 of 66) developed tracheobronchitis. Of these seven patients, two developed a VAP later on. The mean CPIS of the patients with tracheobronchitis was 5.0 (1.7) points and the median number of days on mechanical ventilation at the time of tracheobronchitis was five days (IQR = three to six). Patients with tracheobronchitis required mechanical ventilation during a median of 11 days (IQR $=8.0$ to 25.0 ).

The microorganisms responsible for VAP in this study were: Enterobacteriaceae (45\%), Pseudomonas aeruginosa (20\%), methicillin-resistant Staphylococcus aureus (10\%), Haemophilus influenzae (10\%), Serratia species (10\%) and a range of other microorganisms. VAP was polymicrobial in $25 \%$ of the episodes (5 among the 20 first cases).

Samples were obtained by means of plain endotracheal aspirate $(12 ; 60 \%)$, non-bronchoscopically-guided plugged telescopic catheter $(4 ; 20 \%)$, bronchoscopically-guided plugged telescopic catheter $(3 ; 15 \%)$ and bronchoscopically-guided bronchoalveolar lavage $(1 ; 5 \%)$.

\section{Risk factors}

We analysed preoperative, operative and immediate postoperative risk factors for the development of VAP. In the univariate analysis preoperative factors associated with VAP were (Table $3)$ : mixed ICU (relative risk $[R R]=2.8$ ), peripheral vascular disease $(R R=3)$, renal disease $(R R=7.9)$ and American Society of Anesthesiologists score more than $3(R R=3.5)$. For surgical risk factors, the following were associated with VAP: need for inotropic support ( $R R=15)$, need for intra-aortic balloon $(R R=5.5)$, ascending aorta surgery $(R R=9.7)$ and median duration of surgery. For postoperative risk factors, the following were associated with VAP: mean number of blood units transfused, need for re-intervention $(R R=12.3)$ and days of mechanical ventilation until onset of VAP.

Regarding multivariate analysis, two different models were performed, not including or including the days on mechanical ventilation in the model. As for the logistic regression model 
Table 2

Preoperative and surgical characteristics of patients who underwent major heart surgery

\begin{tabular}{|c|c|}
\hline Characteristic & Global \\
\hline \multicolumn{2}{|l|}{ Preoperative } \\
\hline Number of patients & 971 \\
\hline Mean age in years (SD) & $64.1(12.2)$ \\
\hline Sex, male/female & $690 / 281$ \\
\hline \multicolumn{2}{|l|}{ Underlying conditions (\%) } \\
\hline Myocardial infarction & $351(36.1)$ \\
\hline Congestive heart failure & $125(12.9)$ \\
\hline Central nervous system disorder & $82(8.4)$ \\
\hline Chronic obstructive pulmonary disease & $84(8.7)$ \\
\hline Peripheral vascular disease & $179(18.4)$ \\
\hline Ulcer disease & $51(5.3)$ \\
\hline Diabetes mellitus & $114(11.7)$ \\
\hline Renal disease & $33(3.4)$ \\
\hline Malignant neoplasm & $14(1.4)$ \\
\hline Liver disease & $56(5.8)$ \\
\hline Severe pulmonary hypertension & $29(3.0)$ \\
\hline Severe ventricular dysfunction & $76(7.9)$ \\
\hline Previous cardiac surgery (\%) & $96(9.9)$ \\
\hline Mean Charlson comorbidity index (SD) & $1.6(1.6)$ \\
\hline \multicolumn{2}{|l|}{ McCabe and Jackson groups (\%) } \\
\hline 1 & $68(7.0)$ \\
\hline 2 & $689(71.0)$ \\
\hline 3 & $214(22.0)$ \\
\hline \multicolumn{2}{|c|}{ New York Heart Association functional class (\%) } \\
\hline I & $148(15.2)$ \\
\hline II & $290(29.9)$ \\
\hline III & $390(40.2)$ \\
\hline IV & $143(14.7)$ \\
\hline \multicolumn{2}{|c|}{ American Society of Anesthesiologists score (\%) } \\
\hline 1 & 0 \\
\hline 2 & $10(1.0)$ \\
\hline 3 & $673(69.4)$ \\
\hline 4 & $279(28.7$ \\
\hline 5 & $19(1.9)$ \\
\hline \multicolumn{2}{|l|}{ EuroSCORE (\%) } \\
\hline Low risk (0 to 2 ) & $213(21.9)$ \\
\hline Moderate risk (3 to 6 ) & $407(41.9)$ \\
\hline High risk $(>6)$ & $351(36.1)$ \\
\hline
\end{tabular}


Table 2 (Continued)

Preoperative and surgical characteristics of patients who underwent major heart surgery

\begin{tabular}{|c|c|}
\hline \multicolumn{2}{|l|}{ Surgical } \\
\hline \multicolumn{2}{|l|}{ Indication (\%) } \\
\hline Elective & $781(80.4)$ \\
\hline Urgent & $148(15.2)$ \\
\hline Emergent & $42(4.3)$ \\
\hline \multicolumn{2}{|l|}{ Type of surgery (\%) } \\
\hline Valvular replacement & $267(27.5)$ \\
\hline CABG & $528(54.4)$ \\
\hline Mixed (valvular and CABG) & $76(7.8)$ \\
\hline Heart transplantation & $14(1.4)$ \\
\hline Aortic surgery & $46(4.7)$ \\
\hline Other & $40(4.1)$ \\
\hline Mean duration of surgery (minutes) (SD) & $233(96.0)$ \\
\hline Mean cardiopulmonary bypass time (minutes) (SD) & $110.1(54.1)$ \\
\hline Mean aortic cross-clamp time (minutes) (SD) & $71.9(42.2)$ \\
\hline
\end{tabular}

$\mathrm{CABG}=$ Coronary artery bypass grafting; $\mathrm{SD}=$ standard deviation.

and considering the number of patients with VAP, only the four variables which yielded stable results in all the runs of the jackknifing technique were included. With the use of multivariate analysis (first model), we identified the following significant independent risk factors for VAP (Table 4): ascending aorta surgery $(\mathrm{OR}=6.22 ; 95 \% \mathrm{Cl}=1.69$ to 22.89$)$, number of blood units transfused (OR $=1.08$ per unit transfused; $95 \%$ $\mathrm{Cl}=1.04$ to 1.13 ) and need for re-intervention (OR $=6.65$; $95 \% \mathrm{Cl}=2.10$ to 21.01 ). When 'number of days of mechanical ventilation' was included as a covariate in a separate

\section{Figure 1}

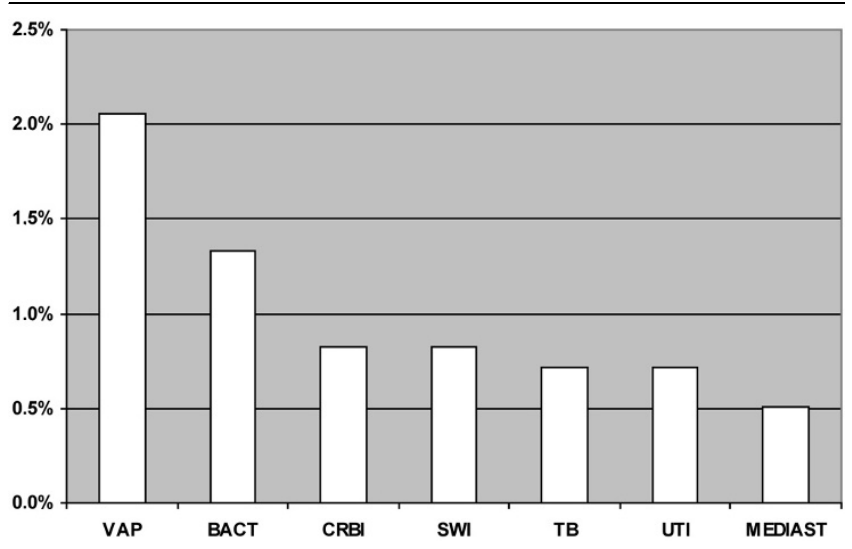

Incidence of nosocomial infections among 971 patients undergoing major heart surgery in Europe. $\mathrm{BACT}=$ bacteraemia; $\mathrm{CRBI}=$ catheterrelated bloodstream infection; MEDIAST = postsurgical mediastinitis; $\mathrm{SWI}=$ surgical wound infection; $\mathrm{TB}=$ tracheobronchitis; $\mathrm{UTI}=$ urinary tract infection; VAP $=$ ventilator-associated pneumonia. model, significant independent risk factors for VAP were: need for re-intervention ( $\mathrm{OR}=11.97 ; 95 \% \mathrm{Cl}=2.76$ to 51.81 ) and days of mechanical ventilation $(\mathrm{OR}=1.41$ per day of mechanical ventilation; $95 \% \mathrm{Cl}=1.24$ to 1.61 ).

\section{Treatment}

Data on antimicrobial management was available from 19 of 20 VAPs. Time elapsed from clinical diagnosis to the start of therapy was classified as: less than 8 hours (9 of $19 ; 47.4 \%$ ), 8 to 24 hours ( 9 of $19 ; 47.4 \%$ ) and more than 48 hours ( 1 of $19 ; 5.2 \%)$. Empirical therapy consisted of one drug (12; $63.2 \%)$, two drugs $(5 ; 26.3 \%)$ and more than two drugs $(2$; $10.5 \%)$. Empirical therapy was changed in 10 patients (52.6\%) due to microbiological data (five patients), absence of clinical response (three patients) or both (two patients). Empirical therapy was considered adequate in 13 patients $(68.4 \%)$. Definite therapy consisted of one drug $(6 ; 31.6 \%)$, two drugs $(8 ; 42.1 \%)$ and more than two drugs $(5 ; 26.3 \%)$.

\section{Outcome}

The median length of stay in the ICU was significantly longer $(P<0.001)$ in patients with VAP than in patients without VAP (23 vs 2 days). Overall ICU mortality in patients who underwent MHS was 3\% (29 of 971). Death was significantly more frequent $(P<0.001)$ in patients with VAP $(35 \%$ vs $2.3 \%)$.

With the use of multivariate analysis, we identified the following significant independent risk factors for mortality: peripheral vascular disease ( $\mathrm{OR}=3.35, \mathrm{Cl}=1.46$ to 7.67 ), intra-aortic balloon ( $\mathrm{OR}=8.21, \mathrm{Cl}=3.38$ to 19.94$)$ and need for re-intervention ( $\mathrm{OR}=3.46, \mathrm{Cl}=1.29$ to 9.26$)$. VAP was, as well, an 
Table 3

\begin{tabular}{|c|c|c|c|c|}
\hline Characteristic & $\begin{array}{l}\text { VAP (\%) } \\
(\mathrm{n}=20)\end{array}$ & $\begin{array}{l}\text { No VAP }(\%) \\
(n=951)\end{array}$ & $\begin{array}{l}\text { Relative risk } \\
\text { (95\% confidence interval }\end{array}$ & $P$ value \\
\hline Mixed ICU & $12(60)$ & $330(34.7)$ & 2.8 (1.1 to 6.9$)$ & 0.02 \\
\hline Peripheral vascular disease & $8(40)$ & $171(18)$ & $3.0(1.2$ to 7.5$)$ & 0.01 \\
\hline Renal disease & $4(20)$ & $29(3)$ & 7.9 (2.5 to 25.2$)$ & 0.004 \\
\hline American Society of Anesthesiologists $>3$ & $12(60)$ & $286(30)$ & 3.5 (1.4 to 8.6$)$ & 0.006 \\
\hline Need for inotropic support & $20(100)$ & $554(58.3)$ & & $<0.001$ \\
\hline Need for intra-aortic balloon & $5(25)$ & $54(5.7)$ & 5.5 (1.9 to 15.8$)$ & 0.005 \\
\hline Ascending aortic surgery & $6(30)$ & $40(4.2)$ & 9.7 (3.5 to 26.7 ) & 0.001 \\
\hline Median surgery duration in minutes (IQR) & 287 (262 to 403$)$ & 210 (170 to 260$)$ & & $<0.001$ \\
\hline Mean number of blood units transfused (SD) & $16.8 \pm 19.5$ & $2.1 \pm 4.4$ & & $<0.001$ \\
\hline Need of re-intervention & $9(45)$ & $59(6.2)$ & $12.3(4.9$ to 31$)$ & $<0.001$ \\
\hline Median number of days on mechanical ventilation (IOR) & 9.5 (5 to 29 ) & $1(1$ to 1$)$ & & $<0.001$ \\
\hline
\end{tabular}

independent risk factor for mortality $(\mathrm{OR}=8.62, \mathrm{Cl}=2.63$ to 28.26).

\section{Discussion}

Our multicentre European study confirms that VAP was the main cause of postoperative infection in patients undergoing MHS in several European centres. Our results showed incidence data between that reported from institutions with very different case mixed.

Figures of incidence of nosocomial infections in general ICUs vary from 9 to 37\%, mostly depending on the type and severity of illness of that population and the definitions used $[19,20]$. In patients undergoing MHS, figures of postoperative nosocomial infections range from 9 to $45 \%$, depending also on the type of heart surgery performed $[1,21]$.

VAP is the most common ICU-acquired infection both in general and surgical ICUs $[4,6]$, and that also holds true in patients undergoing MHS $[1,7,11,22]$; however, rates are very variable and range from 3 to $21.6 \%$ [1,7,8,10,21,23-25], probably depending on the different case mix of the individual reporting institutions.
According to the National Nosocomial Infections Surveillance report of 2004, the median rate of VAP in 47 cardiothoracic surgery ICUs was 6.3 (IQR $=2.9$ to 12.6$)$ per 1000 ventilation days [26]; however, the proportion of patients undergoing MHS in that population is not clear. In a previous study, several European MHS units retrospectively estimated their incidence of VAP which occurred in $3.8 \%$ of all patients undergoing MHS [11]. The present study provides a prospectively collected incidence rate of $2.1 \%$ (incidence density of 13.9 of 1000 ventilation days) which is lower than previous results found in similar patients $[1,7,8]$, although it is comparable with those reported in other studies $[9,10]$.

Microorganisms causing VAP vary considerably according to the characteristics of the patients in the different ICU types, the length of hospital stay and intubation. Common pathogens include $P$. aeruginosa, $S$. aureus and Enterobacteriaceae [27]. There is no evidence that the microorganisms causing VAP after MHS are substantially different $[1,7,9]$ to those in other types of patients in ICUs. In a paper from Kollef and colleagues [1], 59 of 605 MHS patients developed VAP. Enterobacteriaceae (15 cases) and $P$. aeruginosa (9 cases) predominated, as happened in our series. Our series also

Table 4

Risk factors for VAP in patients undergoing major heart surgery in Europe and a multivariate analysis

\begin{tabular}{|c|c|c|c|}
\hline Characteristic & Odds ratio & 95\% confidence interval & $P$ value \\
\hline Ascending aortic surgery & 6.22 & 1.69 to 22.89 & 0.006 \\
\hline Number of blood units transfused (per unit transfused) & 1.08 & 1.04 to 1.13 & $<0.001$ \\
\hline Need for re-intervention & 6.65 & 2.10 to 21.01 & 0.001 \\
\hline
\end{tabular}


showed the potential presence of $S$. aureus and particularly the risk of methicillin-resistant isolates. The proportion of polymicrobial VAP ranged from 13 to $55 \%$ in different studies [28-30]. In our series $25 \%$ of the VAP episodes had more than one microorganism present.

Various risk factors have been associated with the development of VAP in patients undergoing MHS, including the duration of mechanical ventilation, need for reintubation, transfusion needs, empirical administration of broadspectrum antibiotics, type of surgery, age over 60 years, supine position during the first 24 hours, history of chronic obstructive pulmonary disease, NYHA score of 3 or higher and need for mechanical intravascular support $[1,7,8,21,23,24,31]$. Some of these factors were confirmed in our study, in particular, transfusion needs and type of surgery. At the same time, our study underscores other risk factors such as the need for re-intervention with haemorrhage or cardiac tamponade in the immediate postoperative period. Our study was oriented to find preoperative, intraoperative and immediate postoperative factors amenable to intervention in the population undergoing MHS. Due to this, we decided not to include the variable 'days of mechanical ventilation' in the model because it completely overshadowed the importance of the other variables we specifically wanted to address.

Because of this, we decided to include the variable 'days of mechanical ventilation' in a separate model. After analysing this new model, transfusion needs lost statistical significance.

Most unfortunately, the majority of the variables that significantly predict VAP are not amenable to intervention. In our opinion the use of anticipative or pre-emptive antimicrobial therapy should be explored as one of the few potential interventions to avoid VAP in the high-risk population. It is known that inadequate empirical therapy is associated with an increase in VAP-related mortality, even if it is corrected in the following hours. Singh and colleagues demonstrated that the administration of three days of ciprofloxacin to patients with suspicion of VAP had a very favourable impact on the cost and length of antimicrobial use, and reduced the rate of superinfections and the emergence of resistance [32]. Also, the use of oral decontamination, along with three days of cefotaxime or ceftriaxone, has been demonstrated to have the potential benefit of antimicrobial pre-emptive therapy in patients at high risk of VAP $[33,34]$. Other potential preventive measures include continuous aspiration of subglottic secretions [35] or the use of polyurethane cuffed tubes [36].

The overall mortality rate for VAP in patients undergoing MHS may be as high as 16 to $57 \%[1,7,9]$, but many critically ill patients with VAP die because of their underlying disease rather than of pneumonia. Crude mortality rate of patients with VAP was found to be $35 \%$ in our study and attending physicians attributed $13.8 \%$ of excess deaths to VAP. However, it should be stated that because multiple comorbidities in these patients, the attribution of mortality to VAP should always be interpreted with caution.

Some limitations of this investigation should be mentioned. Countries and institutions were not randomly selected among the whole continent and the relative weight of the European countries is not equilibrated. However, this study includes 25 centres from eight European countries and constitutes, to our knowledge, the best data available to date to estimate the dimension of this problem. On the other hand, the number of patients with VAP is relatively low. However, our study population includes almost 1000 cases and during a whole month all patients undergoing operations were systematically included.

\section{Conclusions}

These data, representing several European institutions, suggest that VAP is still the main cause of nosocomial infection during the postoperative period following MHS. Due to the scarcity of variables for intervention, anticipative or pre-emptive antimicrobial therapy should be explored as one of the few potential interventions to avoid VAP in the population remaining under mechanical ventilation for more than 48 hours.

\section{Key messages}

- One or more nosocomial infections were detected in $4.4 \%$ of the patients.

- VAP was the most frequent nosocomial infection $(2.1 \%$, 13.9 episodes per 1000 days of mechanical ventilation).

- The principal microorganisms responsible for VAP in this study were: Enterobacteriaceae (45\%), Pseudomonas aeruginosa (20\%) and methicillin-resistant Staphylococus aureus (10\%).

- Risk factors for VAP were: ascending aorta surgery, number of blood units transfused and need for re-intervention.

- Death was significantly more frequent in patients with VAP (35\% vs $2.3 \%$ ).

\section{Competing interests}

The authors declare that they have no competing interests.

\section{Authors' contributions}

$\mathrm{EB}$ and $\mathrm{JH}$ designed the study. JH wrote the manuscript drafts. PM and GPC were responsible for the analysis of the data. All authors participated in the acquisition of the data and contributed in the writing and critical appraisal of the manuscript. All authors read and approved the final manuscript. EB critically revised the article and gave final approval to the version to be published. 


\section{Authors' information}

The following investigators collaborated in the collection of data in the different hospitals participating in the study collaborating thus with the ESGNI and the EWCl: Peter Mares (AKH University Hospital Vienna, Austria); Kirsten Eliasen (Rigshospitalet, Denmark); Durand Michel (Hopital A Michallon, CHU de Grenoble, France); Rafaele Bonato (Azienda OspedalieraUniversita di Padova, Italy); José Antonio Moreno (Hospital Universitari Germans Trias i Pujol, Spain); Manuel Colmenero (Virgen de las Nieves, Spain); Alvarez Berceruelo (Hospital Clínico de San Carlos, Spain); Armando Maruenda (Hospital Clínico Universitario de Valencia); Primitivo Arribas (Hospital 12 de Octubre. Spain); Roberto Voces (Hospital de Cruces, Spain); José Manuel Borrallo (Meixoeiro, Spain); R. Carlos Marcos (Clínica Puerta de Hierro, Spain); Antonio Reyes (Hospital de la Princesa, Spain); Feliciano Fernández (Virgen de la Macarena, Spain); Mariano Villaseñor (Clínica Ruber, Spain); Leonardo Lorente (Hospital Universitario de Canarias, Spain); Mercedes Cuesta (Ruber Internacional, Spain); Juan Porta (Hospital La Fe, Spain); Rubén Jara-Rubio (Virgen de la Arrixaca, Spain) Johan Sellgren, Sven-Erik Ricksten (Sahlgrens University Hospital, Sweden); Daniel Schmidlin (University Hospital Zurich, Switzerland); Patrick Francioli (Centre Hospitalier Universitaire Vaudois, Switzerland).

\section{Acknowledgements}

The study was supported in part by Ciber de Enfermedades Respiratorias (CIBERES) and by the Rafael del Pino Foundation. We thank Lawrence JC Baron for his review of the English version of the manuscript and Cristina Fernández for her contribution to the statistical analysis. We thank Dr M Desco and Dr J Pascau of the Medical Image Laboratory of Experimental Medicine for their support with the electronic retrieval of the data.

\section{References}

1. Kollef MH, Sharpless L, Vlasnik J, Pasque C, Murphy D, Fraser VJ: The impact of nosocomial infections on patient outcomes following cardiac surgery. Chest 1997, 112:666-675.

2. Welsby IJ, Bennett-Guerrero E, Atwell D, White WD, Newman MF, Smith PK, Mythen MG: The association of complication type with mortality and prolonged stay after cardiac surgery with cardiopulmonary bypass. Anesth Analg 2002, 94:1072-1078.

3. Rello J, Ollendorf DA, Oster G, Vera-Llonch M, Bellm L, Redman $\mathrm{R}$, Kollef $\mathrm{MH}$ : Epidemiology and outcomes of ventilator-associated pneumonia in a large US database. Chest 2002, 122:2115-2121.

4. Vincent JL, Bihari DJ, Suter PM, Bruining HA White J, NicolasChanoin MH, Wolff M, Spencer RC, Hemmer M: The prevalence of nosocomial infection in intensive care units in Europe. Results of the European Prevalence of Infection in Intensive Care (EPIC) Study. EPIC International Advisory Committee. JAMA 1995, 274:639-644.

5. George DL: Epidemiology of nosocomial pneumonia in intensive care unit patients. Clin Chest Med 1995, 16:29-44.

6. Richards MJ, Edwards JR, Culver DH, Gaynes RP: Nosocomial infections in medical intensive care units in the United States. National Nosocomial Infections Surveillance System. Crit Care Med 1999, 27:887-892.

7. Bouza E, Perez A, Munoz P, Jesus Perez M, Rincon C, Sanchez C, Martin-Rabadan P, Riesgo M: Ventilator-associated pneumonia after heart surgery: A prospective analysis and the value of surveillance. Crit Care Med 2003, 31:1964-1970.

8. Leal-Noval SR, Marquez-Vacaro JA, Garcia-Curiel A, CamachoLarana P, Rincon-Ferrari MD, Ordonez-Fernandez A, Flores-Cord- ero JM, Loscertales-Abril J: Nosocomial pneumonia in patients undergoing heart surgery. Crit Care Med 2000, 28:935-940.

9. Pawar M, Mehta Y, Khurana P, Chaudhary A, Kulkarni V, Trehan N: Ventilator-associated pneumonia: incidence, risk factors, outcome, and microbiology. J Cardiothorac Vasc Anesth 2003, 17:22-28.

10. Simsek S, Yurtseven N, Gercekogalu H, Izgi F, Sohtorik U, Canik $\mathrm{S}$, Ozler A: Ventilator-associated pneumonias in a cardiothoracic surgery centre postoperative intensive care unit. $J$ Hosp Infect 2001, 47:321-324.

11. Bouza E, Hortal J, Munoz P, Perez MJ, Riesgo MJ, Hiesmayr M: Infections following major heart surgery in European intensive care units: there is room for improvement (ESGNI 007 Study). $J$ Hosp Infect 2006, 63:399-405.

12. McCabe W, Jackson G: Gram-negative bacteremia, I: etiology and ecology. Arch Inter Med 1962, 110:847-855.

13. Charlson M, Pompei P, Ales K, MacKenzie C: A new method of classifiying prognostic comorbidity in longitudinal studies: development and validation. J Chronic Dis 1987, 40:373-383.

14. American Society of Anesthesiologists: New classification of physical status. Anesthesiology 1963, 24:111.

15. Nashef SAM, Roques F, Michel P, Gauducheau E, Lemeshow S, Salomon R: European system for cardiac operative risk evaluation (EuroSCORE). Eur J Cardiothorac Surg 1999, 16:9-13.

16. Pugin J, Auckenthaler R, Mili N, Janssens JP, Lew PD, Suter PM: Diagnosis of ventilator-associated pneumonia by bacteriologic analysis of bronchoscopic and nonbronchoscopic "blind" bronchoalveolar lavage fluid. Am Rev Respir Dis 1991, 143:1121-1129.

17. Garner JS, Jarvis WR, Emori TG, Horan TC, Hughes JM: CDC definitions for nosocomial infections, 1988. Am J Infect Control 1988, 16:128-140.

18. Ang RP: Use of the Jacknife statistic to evaluate result replicability. J Gen Psychol 1998, 125:218-228.

19. Girou E, Stephan F, Novara A, Safar M, Fagon JY: Risk factors and outcome of nosocomial infections: results of a matched case-control study of ICU patients. Am J Respir Crit Care Med 1998, 157:1151-1158.

20. Legras A, Malvy D, Quinioux Al, Villers D, Bouachour G, Robert R, Thomas R: Nosocomial infections: prospective survey of incidence in five French intensive care units. Intensive Care Med 1998, 24:1040-1046.

21. Rebollo MH, Bernal JM, Llorca J, Rabasa JM, Revuelta JM: Nosocomial infections in patients having cardiovascular operations: a multivariate analysis of risk factors. J Thorac Cardiovasc Surg 1996, 112:908-913.

22. Bouza E, Hortal J, Munoz P, Pascau J, Perez MJ, Hiesmayr M: Postoperative infections after major heart surgery and prevention of ventilator-associated pneumonia: a one-day European prevalence study (ESGNI-008). J Hosp Infect 2006, 64:224-230

23. Zickman B, Sablotzki A, Fussle R, Gorlach G, Hempelmann G: Perioperative microbiologic monitoring of tracheal aspirates as a predictor of pulmonary complications after cardiac operations. J Thorac Cardiovasc Surg 1996, 111:1213-1218.

24. Gaynes R, Bizek B, Mowry-Hanley J, Kirsh M: Risk factors for nosocomial pneumonia after coronary artery bypass graft operations. Ann Thorac Surg 1991, 51:215-218.

25. Carrel T, Schmid ER, von Segesser L, Vogt M, Turina M: Preoperative assessment of the likelihood of infection of the lower respiratory tract after cardiac surgery. Thorac Cardiovasc Surg 1991, 39:85-88.

26. National Nosocomial Infections Surveillance (NNIS) System Report, data summary from January 1992 through June 2004, issued October 2004. Am J Infect Control 2004 32:470-485.

27. Chastre J, Fagon JY: Ventilator-associated pneumonia. $A m \mathrm{~J}$ Respir Crit Care Med 2002, 165:867-903.

28. Bryan CS, Reynolds KL: Bacteremic nosocomial pneumonia. Analysis of 172 episodes from a single metropolitan area. Am Rev Respir Dis 1984, 129:668-671.

29. Chastre J, Trouillet JL, Vuagnat A, Joly-Guillou ML, Clavier H, Dombret MC, Gibert C: Nosocomial pneumonia in patients with acute respiratory distress syndrome. Am J Respir Crit Care Med 1998, 157:1165-1172.

30. Fagon JY, Chastre J, Domart Y, Trouillet JL, Pierre J, Darne C, Gibert C: Nosocomial pneumonia in patients receiving continuous mechanical ventilation. Prospective analysis of 52 episodes 
with use of a protected specimen brush and quantitative culture techniques. Am Rev Respir Dis 1989, 139:877-884.

31. Kollef $\mathrm{MH}$ : Ventilator-associated pneumonia. A multivariate analysis. JAMA 1993, 270:1965-1970.

32. Singh N, Rogers P, Atwood CW, Wagener MM, Yu VL: Shortcourse empiric antibiotic therapy for patients with pulmonary infiltrates in the intensive care unit. A proposed solution for indiscriminate antibiotic prescription. $A m$ J Respir Crit Care Med 2000, 162:505-511.

33. Sanchez Garcia M, Cambronero Galache JA, Lopez Diaz J, Cerda Cerda E, Rubio Blasco J, Gomez Aguinaga MA, Nunez Reiz A, Rogero Marin S, Onoro Canaveral JJ, Sacristan del Castillo JA: Effectiveness and cost of selective decontamination of the digestive tract in critically ill intubated patients. A randomized, double-blind, placebo-controlled, multicenter trial. Am J Respir Crit Care Med 1998, 158:908-916.

34. van Saene HK, Petros AJ, Ramsay G, Baxby D: All great truths are iconoclastic: selective decontamination of the digestive tract moves from heresy to level 1 truth. Intensive Care Med 2003, 29:677-690.

35. Bouza E, Perez MJ, Munoz P, Rincon C, Barrio JM, Hortal J: Continuous aspiration of subglottic secretions in the prevention of ventilator-associated pneumonia in the postoperative period of major heart surgery. Chest 2008, 134:938-946.

36. Poelaert J, Depuydt P, De Wolf A, Velde S Van de, Herck I, Blot S: Polyurethane cuffed endotracheal tubes to prevent early postoperative pneumonia after cardiac surgery: a pilot study. J Thorac Cardiovasc Surg 2008, 135:771-776. 